\title{
Therapeutic Importance of Curcumin with a Special Emphasis on Mdr Cancer Cells and the Factors Influencing Pharmacodynamics
}

\author{
Muhasina K M, Dhanabal S. Palaniswamy*, Deepika, N P, Divya jyothi Palati \\ Department of Pharmacognosy, JSS College of Pharmacy, JSS Academy of Higher Education \& Research, Ooty \\ - 643001, The Nilgiris, Tamil Nadu, India
}

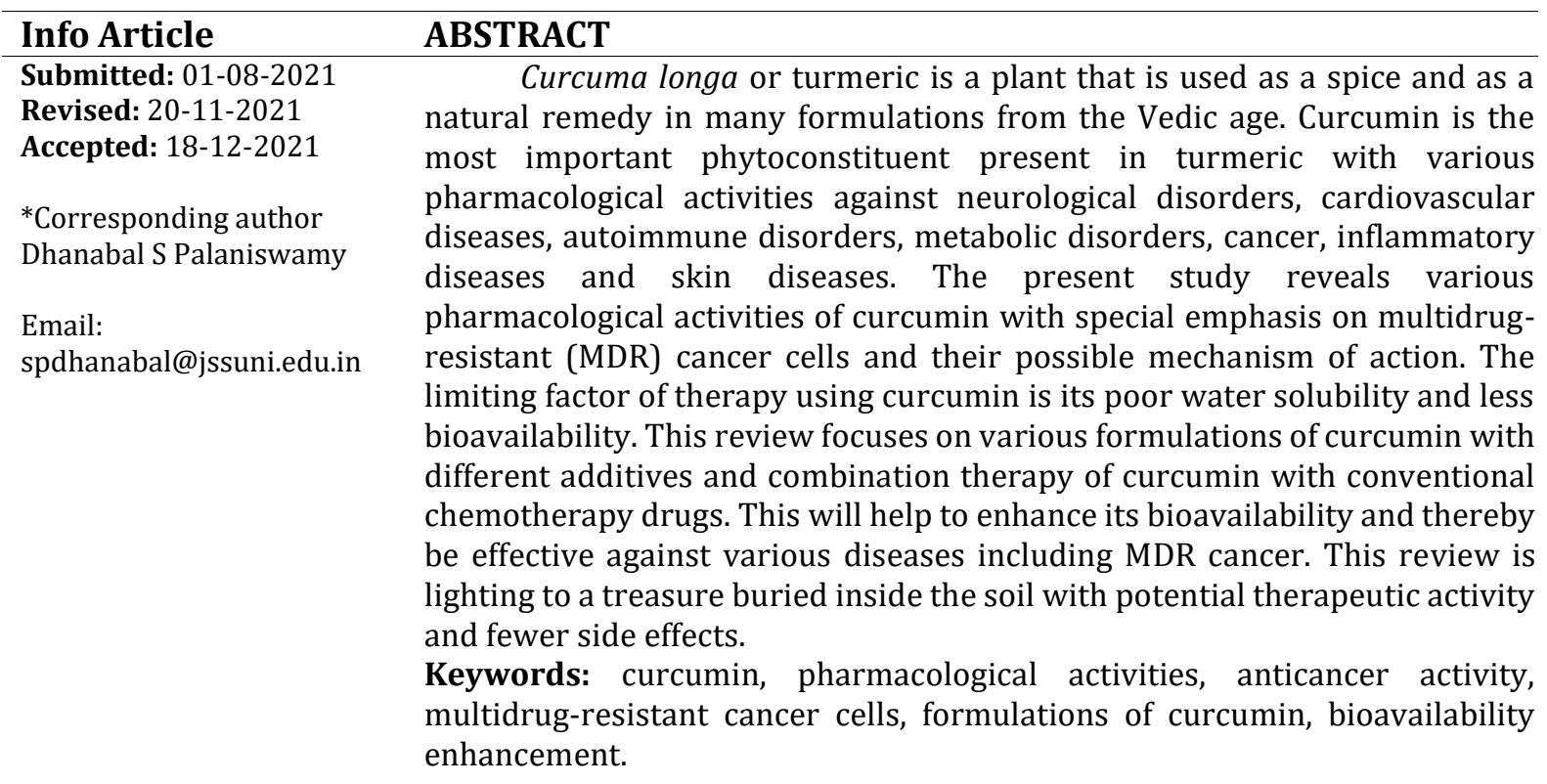

\section{INTRODUCTION}

Turmeric was used as a functional food and as a home remedy for different diseases from the ancient period in India and was prepared from the plant Curcuma longa (Orellana-Paucar et al., 2013). The medicinal values of turmeric have been known from the Vedic ages and are reported in ancient texts. The recent studies showed its real mechanism of action and its wide pharmacological activities. It has been widely used in Asian countries as a medicinal plant and as a spice due to its antimicrobial, antioxidant, anti-cancer, and antimigraine actions. The anti-cancer activity of curcumin is due to its various mechanism of action on different target molecules (Schaffer et al., 2011). Curcumin was one of the potential phytoconstituent that have been studied mostly against cancer because of its versatile therapeutic activity including anti-oxidant, anti-proliferative, apoptosis induction and anti-inflammatory activities. Even though cancer therapy developed drastically over the decade, there are numerous side effects of existing therapies and that is sighting to the hope for phytoconstituents for fighting cancer

According to studies, there was a relationship between various food habits and carcinogenesis. It was proven by the studies in different ethnic groups. In the Asian population, some cancer such as prostate, breast, and gastrointestinal tract cancers had less prevalence because of their food habits or dietary intake of polyphenols from green tea (Khan and Mukhtar, 2008), quercetin from onions (Pan, Zheng and Ho, 2018), resveratrol from grapes (Rauf et al., 2018), curcumin from turmeric (Unlu et al., 2016), genistein-soy flavonoid (Farina et al., 2006), etc. Phytochemicals show anti-cancer activity due to their multi-target mechanism of actions such as anti-proliferative and anti-mutagenic activities. So, they are considered a promising anticancer agent (Enrico, 2019).

Curcumin is a polyphenol compound evolved from the turmeric plant and the extensive research on this compound for the past 50 years indicates that curcumin can prevent (Cheng et al., 
2000) and treat cancer (Zoi et al., 2021)The studies also provide shreds of evidence for suppression of initiation, promotion, and metastasis of tumors. Curcumin shows very little or no toxicity pharmacologically. Human clinical trials point that no dose-limiting toxicity when using doses up to 10 $\mathrm{g} /$ day. All this research indicates that curcumin has tremendous potential in cancer therapy. But functional food scientists feel difficulty because of the solubility and bioavailability issues of curcumin. The low solubility, higher degradability and low bioavailability of curcumin are the main problems associated with curcumin as a functional food (Tsuda, 2018).

More than 100 compounds separated from turmeric to date and the main constituents of turmeric are curcuminoids like curcumin $(77 \%)$, demethoxycurcumin $\quad(17 \%), \quad$ and bisdemethoxycurcumin (3\%), as well as volatile oils such as atlantone, turmerone, and zingiberene, other compounds like proteins, sugars, and resins. In these phytoconstituents, curcuminoids and turmerone have a vast variety of pharmacological actions (Hewlings and Kalman, 2017). Curcumin has profound medicinal values among the several natural remedies and that interested researchers to do further research on curcumin (Prasad and Tyagi, 2015). Curcumin exhibited a wide variety of actions like bactericidal, anti-inflammatory, antimicrobial, and anti-cancer activities (Grynkiewicz and Ślifirski, 2012; Faden et al., 2016). Scientific research proved the greater efficacy of curcumin, to act against numerous diseases without side effects (Karlstetter et al., 2011).

Curcumin showed potential activity as an anti-cancer agent by its activity of suppressing the tumour cell proliferation, downregulation of transcription factors like COX-2, NF-kB, Egr-1, AP1, LOX, MMP-9, NOS, UPA, TNF, cyclin DI, chemokines, and cell surface adhesion molecules, down-regulate growth factor receptors (HER2 \& EGFR); and inhibit the activity of c-Jun N-terminal kinase, protein tyrosine kinases, and protein serine/threonine kinases. All these factors point out the ability of curcumin against cancer cells. The activity of curcumin is suppressed by its bioavailability issues. Some of the formulations of curcumin available in the market show higher bioavailability and absorption. All this points to the scope for an effective therapeutic alternative for cancer with fewer side effects and higher potential (Aggarwal, Kumar and Bharti, 2003).

Chemo-resistance mainly occurs in clinical treatment, resulting in poor prognosis and recurrence of the disease. Alternative treatments like Chinese medicine light the new therapeutic modes to overcome chemo-resistance. It has been already demonstrated that MDR can be modulated by several plant secondary metabolites. Many cancer cells are resistant to chemotherapy and they are defective in apoptosis induction. The natural products which are based on non-apoptotic programmed cell death can be used as therapeutic agents for multi-drug resistant cancer and are considered a promising anti-cancer agent (Faden $e t$ al., 2016).<smiles>COc1cc(/C=C/C(=O)CC(=O)/C=C/c2ccc(O)c(OC)c2)ccc1O</smiles>

Figure 1: Structure of curcumin.

\section{PHARMACOLOGICAL ACTIVITIES IN GENERAL}

\section{Neurodegenerative disorders}

Malfunctioning of normal mechanisms of the central and peripheral nervous system leads to neurological disorders (Lavoie et al., 2009). Examples of this include epilepsy, Parkinson's disease, Alzheimer's disease (AD), migraines, and traumatic disorders (Santos et al., 2015). Lifestyle, serious cranial-cerebral injuries, cardiovascular diseases, and type- 2 diabetes, etc can lead to the development of $\mathrm{AD}$. The amyloidal cascade hypothesis is a prominent theory for $\mathrm{AD}$ development. But at the same time, over phosphorylation of tau protein is also important in the aetiology of this disease (Zhang et al., 2012). The neuroprotective properties of turmeric have been proved by research (Tęcza and Żylińska, 2016).

Recent studies conducted in vivo indicate that in transgenic $\mathrm{AD}$ mouse models, curcumin by unknown mechanisms can minimize $A \beta$-related pathology (Kim et al., 2005). A $\beta$ binding can be enhanced by curcumin and avoiding the deposition of plaques and preventing cellular insults (GarciaAlloza et al., 2007). Decreasing the serum level of $A \beta$ and attenuating microglial activation and the reduced inflammation in $\mathrm{AD}$ can rescue the distorted neuritis morphology near $A \beta$ plaques by the curcumin (Tang et al., 2018). Reduction of Tau protein processing and phosphorylation also have 
been done by curcumin. In some studies, it is shown that $\alpha$-synuclein aggregation can be modulated by curcumin (Sharma and Nehru, 2018). Parkinson disease is marked by the abnormal aggregation and accumulation of the $\alpha$-synuclein. Because of this pharmacology of curcumin, it can be considered as a prominent drug in molecular target therapies of Parkinson's and other synucleopathies (Tripanichkul and Jaroensuppaperch, 2012).

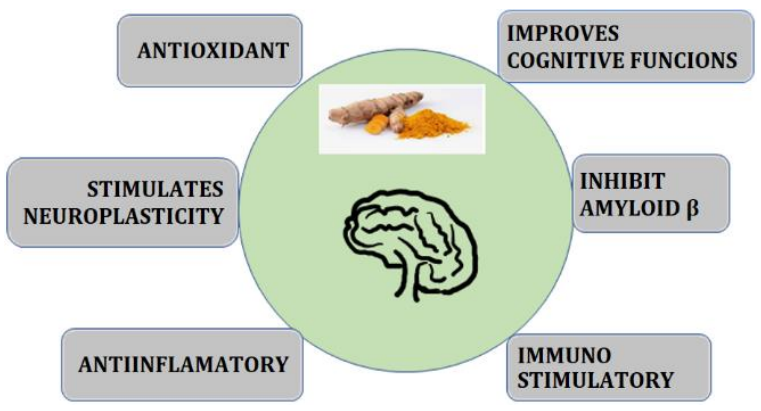

Figure 2. Activity of curcumin on neurodegenerative diseases.

Curcumin can also improve locomotion, microglial activation (Hickey et al., 2012), reduce Huntington's protein aggregation (Chongtham and Agrawal, 2016) and ameliorate disorder signs by the suppression of cell death (Sanmukhani et al., 2014). In a study, depressive disorders were treated with curcumin and that treatment has been effective in improving mood swings (Lopresti et al., 2014) and also altered the biomarkers present in the patients (Lee et al., 2014). Curcumin showed activity on depression and it was proven that turmeric is the potential and safe compound for this disease (Lopresti et al., 2015).

\section{Cardiovascular diseases:}

Cardiovascular diseases are the disease of the heart and the circulatory system supporting it, such as acute myocardial infarction, acute coronary syndrome, and dyslipidaemia. Curcumin can inhibit oxidative stress, inflammation, and apoptosis thereby exerting protective effects on the cardiovascular system. Curcumin influenced lipoprotein metabolism by reduction of triglycerides, LDL, and augmentation of HDL (Ganjali et al., 2017). In a study in patients who are undergoing curcumin therapy, curcumin decreased cardiovascular risk factors such as coronary heart disease, triglyceride, LDL and VLDL with a considerable increase of HDL levels (Mirzabeigi et al., 2015). The efficacy of phospholipidated curcumin showed that it can improve different pathophysiological features of Non-Alcoholic Fatty Liver Disease (NAFLD). This study shows that phospholipidated curcumin capsules with $100 \mathrm{mg}$ of curcumin for 8 days can reduce NAFLD severity (Panahi et al., 2019). In another study, P300-HAT inhibitory effects and calcium(Ca) homeostasis of curcumin are studied and it was proven. Curcumin's anti-inflammatory activity have some effects on atrial arrhythmias and on correcting homeostasis and thereby prevention of some ventricular arrhythmias (Keihanian et al., 2018).

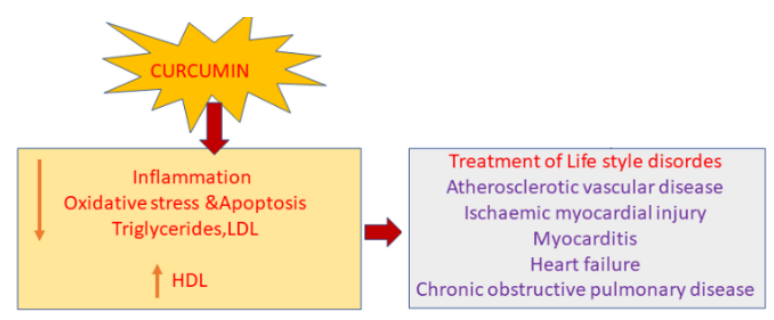

Figure 3 .Cardioprotective mechanisms of curcumin.

\section{Autoimmune diseases}

A disease in which the body was mistakenly attacked by its immune system was known as an auto-immune disease. Inflammatory bowel disease, arthritis, psoriasis, multiple sclerosis (MS), type-I diabetes mellitus, etc are common examples of autoimmune diseases (Funk et al., 2006). Many kinds of research showed that the effectiveness of curcumin against autoimmune diseases (Xie et al., 2009). The efficacy of well-characterized turmeric extracts for the treatment of arthritis at in-vivo conditions and clinical trials was shown that the inflammation was prevented (Panahi et al., 2014).

The main characteristic of inflammatory bowel disease is gastrointestinal tract inflammation. Turmeric has potent activity against inflammation and in one study a pure preparation of curcumin was administered in an open-label study to five Crohn's disease patients and five with ulcerative colitis (UC) (Singla et al., 2014). All UC and CD patients showed better results by using curcumin (Rudrappa and Bais, 2008).

\section{Metabolic disorders like obesity and diabetes.}

Curcumin was played an important action in the control of metabolic disorders like diabetes and obesity. In a study, curcumin extract was used for prevention of diabetes and the group treated with curcumin showed no development of diabetes. This study also showed the changes in the $\beta$-cell functions and also demonstrated that curcumin 
intervention will be beneficial in a prediabetic population (Su, Wang and Chi, 2017).

Another research proved the pharmacological action of curcumin on glucose and lipid metabolism in Type-II diabetic rat models. By enhancing the sensitivity of insulin, curcumin can improve lipid and glucose metabolism. The FFA and TNF- $\alpha$ also decreased and this was also correlated with the curcumin mechanism to improve resistance to insulin (Chiu et al., 2009). Curcumin also prevents kidney abnormalities due to diabetes (Alappat and Awad, 2010) and has an important role in regulating lipid metabolism (Holt, Katz and Kirshoff, 2005).

\section{Anti-bacterial, anti-fungal and anti-viral activities.}

Curcumin treatment reduced the pathogenicity of P.aeroginosa, C. elegance, A.thaliana infection models (Liu and Huang, 2012). Some studies showed that curcumin-loaded microemulsions can be used as an alternative treatment of S.epidermidis associated diseases and for acne vulgaris (Waghmare et al., 2017). The aqueous extract of the drug showed anti-bacterial activity against S.aureus, S.epidermidis, etc (Rai et al., 2008). Due to the potential of NF-KB inhibition of curcumin, it was showed effectiveness against H.pylori infections (Koosirirat et al., 2010). The enhancement effect of curcumin against bacterial infection with staphylococcus aureus with several antibiotics was also studied and the results showed that curcumin increased the potency of antibiotics such as cefixime, vancomycin, cefotaxime, and tetracycline. But curcumin alone shows lesser activity when compared to combination therapy (Barthelemy et al., 1998; Moghaddam et al., 2009).

Various curcumin derivatives showed the significant inhibition of Tat transactivation of HIV1 (Barthelemy et al., 1998). It has significant activity against HIV (Prasad and Tyagi, 2015)and the clear liquid soaps prepared using turmeric extract showed that it has physical and chemical stability and did not change the antimicrobial activity (Ungphaiboon et al., 2005). The boron complexes of curcumin showed time-dependent inactivation of the proteases of HIV-1 and HIV-2 (Sui et al., 1993). In another study, it was proven that the recruitment of RNA polymerase II was affected by curcumin (Kutluay et al., 2008). In patients with liver diseases caused by HIV infection, curcumin extract can be used as a safe and effective medicine (Kim et al., 2009). Curcumin can be used as a cytotoxic agent in cervical carcinoma developed by the infection of human papillomavirus, (Prusty and Das, 2005) by the regulation of AP-1 transcription factor (Foryst-Ludwig et al., 2004; Divya and Pillai, 2006).

\section{Anticancer activity}

Curcumin showed activity against ovarian, uterine (Li et al., 2014), breast (Liu and Ho, 2018), and cervical cancer (Ghasemi et al., 2019). And also curcumin inhibits human prostate cancer stem cell proliferation (Liu et al., 2017), in vitro invasion, and xenografts models (Rivera et al., 2017). In vitro cell line studies showed the potential of curcumin to suppress tumour growth by inhibiting activator protein-1(Weber et al., 2006), NF-kB (Ghasemi et al., 2019), cyclooxygenase-2 (Handler et al., 2007), nitric oxide synthase (Bengmark, 2006), MMP-9 (metalloproteinase-9) (Saja et al., 2007) and STAT3 (signal transducer and activator of transcription 3) (Saydmohammed, Joseph and Syed, 2010).

In the activation of cell cycle arrest, curcumin may serve as an effective agent against cancer cell proliferation (Peng et al., 2014).On antihuman osteosarcoma, the effect of curcumin nanoparticles is studied and proved that curcumininduced apoptosis cell death (Wang et al., 2019). Curcumin exhibited cytotoxicity in Non-Small Cell Lung Cancer (NSCLC) and thereby curcumin is considered as an efficacious therapeutic agent for NSCLC (Hu et al., 2018). Curcumin has significant action to inhibit the proliferation of a wide range of breast cancer cell lines (Tseng et al., 2019) and is effective against leukaemia potentially (Kouhpeikar et al., 2019).

\section{MDR CANCER CELLS}

The compounds present in spices possess potential therapeutic activities like anti-oxidant, anti-mutagenic, anti-inflammatory, and anticancer properties. In P- Glycoprotein (P-gp) mediated multi-drug resistant human cancer cells ERK1 and ERK2 activities are downregulated. ERK1 or ERK2 can be considered as a potential drug target for circumventing multi-drug-resistant human cancer cells. Control over metabolic regulation is the silver lining to correct pathway resistance in MDR tumour cells. Many mechanisms are causing multiple drug resistance, such as P-gp for decreased drug accumulation in intracellular space. In human MDR cancer, ABCB1/ P-gp mediated multidrug resistance involved several transduction pathways and transcription factors (Sui, Fan and Li, 2012). 


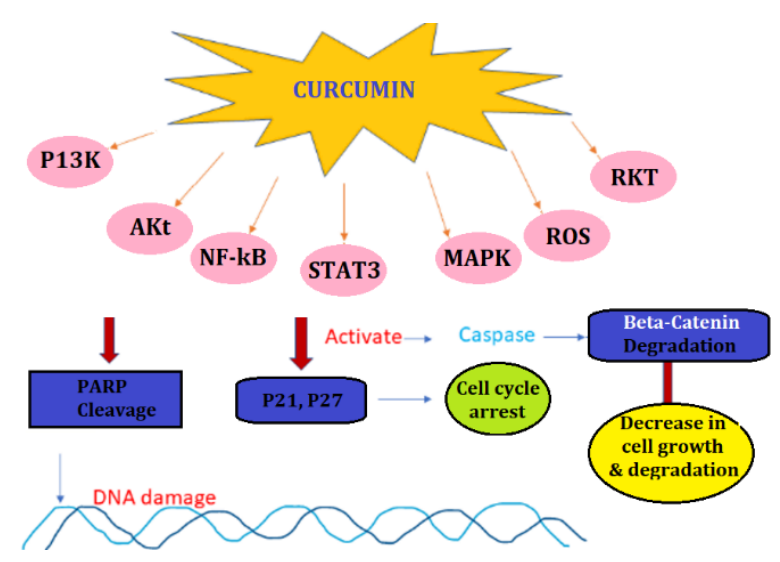

Figure 4: Various mechanisms of curcumin for tumour inhibition.

There was a different mechanism of action by phytochemicals for the prevention of cancer initiation and invasion by integrated signalling pathways in highly resistant multiple myeloma cells. A large group of proteins is involved in the control of metabolism and homeostasis pathways, such as the reaction related to metabolic generation, respiration, glycolysis and lipids, amino acids, and nucleic acid metabolisms. It was already reported in works of literature that the relationship between cancer chemoresistance and metabolic reprogramming in $\mathrm{P}$-gp mediated multidrug resistance.

In hepatocellular carcinoma cells, extracellular signal-regulated kinase activities are down-regulated, so they are considered as potential drug targets of obstacles in MDR- HCC cells. MDR is a common barrier in cancer therapy. Nano delivery of medicine can make some changes in drug delivery, but the payload of drugs is low in nanocarriers than the conventional methods and thereby compromises the treatment outcomes (Mohammad et al., 2019). Phytomedicine has a greater ability to delay the progression of cancer cells and thereby enhance the efficacy of anticancer agents (Yang et al., 2011).

\section{Curcumin effect on MDR cancer cells:}

Bioactive constituents of natural products were contributed to reversing of multidrug resistance of cancer cells, improving the efficacy of already proven anticancer agents, and also reducing the side effects of chemotherapy. By blocking and downregulating the P-gp activity, curcumin rhizomes help to activate the sensitivity of doxorubicin and reverse the MCF-7 breast cancer cells resistance. In combination therapy, two or more therapeutic agents were used to enhance the therapeutic outcome. If the combination of therapeutic agents were used for cancer treatment, it will improve the outcome by synergistic activity or by reducing the multidrug resistance of cancer-treating agents. Meanwhile different varieties of phytochemicals are derived and used for cancer treatment due to their high potential and fewer side effects (Zhong et al., 2018). In phytotherapy, the extracts are used for the treatment. In this, the secondary metabolites will not be single. A plant extract may contain numerous secondary metabolites such as phenols, terpenoids, alkaloids, etc. There are several hundreds of minor components present in phytomedicine, showing a wide variety of pharmacological actions. Because of this, there may be additive actions in the therapeutic potential of plant medicine. Therefore, we considered that synergy was the main reason for the positive impact of phytomedicine (Eid, El-Readi and Wink, 2012).

Curcumin suppresses ABC family transporters in cancer cells, including ABCA1, ABCB1, ABCC1, and ABCG2. Curcumin inhibits the mechanism of the P-gp/ABCB1 protein in cervical cancer cells by engaging with the P-gp binding site on the cell surface and by connecting with the P-gp active sites, resulting in a considerable reduction in the mechanism of this transporter. When these cells are treated with curcumin and vinblastine, vinblastine accumulates within the cells and thereby increasing the sensitivity of the cells (Limtrakul, Anuchapreeda and Buddhasukh, 2004; Zhang et al., 2014).

Curcumin has been demonstrated to inhibit the activity of ABCG2 and increase the reactivity of tumour cells (Chearwae, Shukla, Limtrakul, \& Ambudkar, 2006). Curcumin suppresses Bcl-2, MDR1 and BCR/ABL gene expression in these cells and enhancing doxorubicin efficiency by eliminating the resistance of cells (Misra and Sahoo, 2011). As a result, curcumin can be used in conjunction with other key chemotherapeutic drugs.

The prevention of DNA damage generated by anticancer medicines was another mechanism in the treatment of resistant cancer. Numerous studies show curcumin inhibits repair of DNA special enzymes and also causes the damage of DNA in various cell lines (Lu et al., 2009; Rowe et al., 2009) and $20 \mu \mathrm{M}$ of curcumin reduces the expression of DNA damage-response genes (Lu et al., 2009). According to other studies curcumin 
produces DNA damage, modulates BRCA1, and keeps this in the cytoplasm in triple-negative breast cancer cells and causes apoptosis in these cells (Rowe et al., 2009).

NF-kB produces antiapoptotic proteins and increases MDR production in cancer cells, resulting in cell survival and resistance (Xia et al., 2018). Curcumin lowers the expression of genes controlled by NF-kB such as TNF, COX-2, IL-6, Bcl2 , and Bcl-xl in different cancer cells by inhibiting constitutive NF-kB activity and blocking NF-kB and DNA binding (Shishodia et al., 2005). Downregulation of NF-kB in the presence of curcumin has been reported in cell lines by restriction of proliferation resulting in cellular accumulation in the G1 phase and S phase and thereby increasing cell sensitivity to medicines (Shishodia et al., 2005; Meiyanto et al., 2014).

In human head and neck squamous cell cancer cell lines, overexpression and continuous NF-kB activity have been found and curcumin has been shown to reduce the NF-kB by inhibiting IBkinase (Aggarwal et al., 2004). Curcumin also inhibits the PI3K/AKT pathway, which inhibits NF$\mathrm{kB}$ expression. Suppression of NF-kB directly affects P53 activation, whereas inhibition of VEGF and COX-2 genes decreases cancer cells angiogenesis.

In mice with human gastric cancer xenografts, the combination of 5-fluorouracil and curcumin significantly lower tumour growth when compared to 5-FU alone. According to the findings, this will lower the levels of NF-kB and COX-2 proteins. Curcumin was recommended as a wellknown natural chemical that decreased NF-kB activity and enhanced cancer cells treatment susceptibility (Mortezaee et al., 2019). Curcumin also decreases the activity of cyclin D1 through NF$\mathrm{kB}$ inhibition, found in squamous cell carcinoma of the neck and head (Aggarwal et al., 2004).

\section{BIOAVAILABILITY OF CURCUMIN:}

Curcumin had some limiting factors such as low oral bioavailability and low aqueous solubility, which will hamper its application as a therapeutic agent. Different technologies are applied to overcome this problem and make curcumin more effective. In a study using A549- human lung cancer cell lines novel curcumin-loaded mixed micelles were prepared by using the solvent evaporation method to increase the oral bioavailability and cytotoxicity and the results revealed that a significant improvement in oral bioavailability and cytotoxic action of curcumin formulation as compared to curcumin. So curcumin micelles can be considered as important carrier systems for hydrophobic agents like curcumin with potential improvement in their oral bioavailability (Patil et al., 2015).

The curcumin nanoparticle efficacy against paclitaxel-resistant ovarian cancer cells was studied. The results state that curcumin nanoparticles showed gentler and slow-release than free drug release. The P-gp content of the cell lines resistant to adriamycin was reduced significantly by the curcumin nanoparticles. Phospholipid nanoparticles with taxol and curcumin had improved the stability and solubility with the effect of a slow-release rate. Curcumin is also able to overcome the multidrug resistance of tumour cells by increasing the paclitaxel concentration in the tumour cells to improve the activity of this combination therapy (Z. Liu et al., 2016).

\section{Formulations of Curcumin with higher bioavailability.}

The less bioavailability and a variety of pharmacological actions of curcumin lead to the invention of different formulations of curcumin with a variety of combinations including liposomes, microemulsions, phospholipid complexes, nanoparticles, and polymeric micelles. Studies show that there is a considerable increase in the bioavailability of curcumin in combinations. ETOcur (Essential turmeric oils and curcumin) has increased around 7-8 times higher bioavailability than standard curcumin. In vitro and in vivo studies, it is showing the inhibition of growth of colon cancer cells. The anti-inflammatory property of the ETO-Cur combination is higher than standard curcumin (Toden et al., 2017). The factors that limit curcumin's usefulness and effectiveness are low bioavailability due to its less water solubility and rapid metabolism of inactive metabolites. Because of its high oil solubility and degradability in alkali, many formulations have been developed to enhance its dispersibility and solubility in water to enhance its consequent bioefficacy. In this review, we consider the higher bioavailable formulations of curcumin and its pharmacological actions. Some of them are mentioned here.

Biocurcumax $^{\text {TM }}$ (BCM-95®)

It is a formulation in which curcumin is combined with turmerone, the essential oil of turmeric. The human bioavailability of curcumin is 6.9\% higher than curcumin's raw form (Antony et al., 2008). 
Table I. Bioavailability enhanced formulations of curcumin.

\begin{tabular}{|c|c|c|c|}
\hline $\begin{array}{c}\text { Serial } \\
\text { no }\end{array}$ & Formulation & $\begin{array}{c}\text { Techniques to enhance } \\
\text { bioavailability }\end{array}$ & RB Curcumin \\
\hline 1. & $\begin{array}{l}\text { BCM-95® } \\
\text { (Bio Curcumx®) }\end{array}$ & Turmeric oil & 27 fold (Antony et al., 2008). \\
\hline 2. & $\begin{array}{l}\text { Curcumin C3 } \\
\text { Complex® }\end{array}$ & Piperine & $\begin{array}{l}20 \text { fold (Kaur, Invally and Chintamaneni, } \\
\text { 2016). }\end{array}$ \\
\hline 3. & NovaSol ${ }^{\circledR}$ F & $\begin{array}{l}93 \% \text { Tween-80, and } 7 \% \text { curcumin } \\
\text { powder-liquid micelles. }\end{array}$ & 185 fold (Ranjan et al., 2012). \\
\hline 4. & Cavacurcumin $\AA$ & Gama-Cyclodextrin & 85 fold (Schiborr et al., 2014). \\
\hline 5. & Meriva ${ }^{\circledR}$ & Microcrystalline cellulose/Lecithin & 48 fold (Purpura et al., 2018). \\
\hline 6. & CurcuWIN $®$ & Cellulosic derivatives & 136.3 fold (Cuomo et al., 2011). \\
\hline 7. & $\begin{array}{l}\text { Micronized } \\
\text { Curcumin }\end{array}$ & Silicon dioxide/triacetin/Panadon & 9 fold (Jäger et al., 2014). \\
\hline 8. & CurcuminPro & Whey protein & 100\% (W. Liu et al., 2016). \\
\hline 9. & CurQfen® & Galactomannan fiber & 15.8 times (Im et al., 2012). \\
\hline 10 & Theracurcumin $®$ & $\begin{array}{l}\text { Ghatti } \\
\text { gum/glycerine/Lipids/hydroxy } \\
\text { methylcellulose }\end{array}$ & 15.9 times (Sasaki et al., 2011) \\
\hline 11. & $\begin{array}{l}\text { MicroActive } \\
\text { Curcumin }\end{array}$ & Cellulose/sodium algenate & 9.7 times (Madhavi and Kagan, 2014) \\
\hline 12. & Longvida $®$ & $\begin{array}{l}\text { Docosahexaenoic } \\
\text { acid/Lecithin/Stearic acid }\end{array}$ & $100 \%$ (Gota et al., 2010) \\
\hline
\end{tabular}

\section{Curcumin C3 Complex®}

To enhance the oral absorption of curcumin, piperine is the bioavailability enhancer used in this formulation. Uridine diphosphateglucuronosyltransferase improves the freely available curcumin in the blood. With piperine, curcumin is showing 20 fold higher bioavailability than unformulated curcumin (Kaur, Invally and Chintamaneni, 2016; Ranjan, Mohapatra and Das, 2020).

NovaSol $®$ (micellar curcumin)

The solubility of certain drugs which is hydrophilic can be improved by forming micelles. Novasol is a drug that consists of curcumin powder and Tween-80. It shows 185 fold higher bioavailability than unformulated curcumin. The dissolution and absorption of the drug can be improved by the formation of liquid micelles(Schiborr et al., 2014).

Cavacurmin ${ }^{\circledR}$

It is a formulation based on $\gamma$-cyclodextrin. The bioavailability of the curcumin has been increased by 85 fold in comparison to unformulated curcumin. Up to the upper intestinal tract, cava curcumin is transported unchanged through the stomach, where human amylases works and curcumin molecules are absorbed and cyclodextrin molecules are hydrolyzed (Purpura et al., 2018).

Meriva ${ }^{\circledR}$

It is formulated by curcuminoids (18-20\%) with microcrystalline cellulose and soy lecithin. When compared with an unformulated curcuminoid mixture Meriva has 29 fold higher absorption. Lecithin provides higher bioavailability of desmethoxy curcumin in Meriva (Cuomo et al., 2011).

CurcuWin $®$

It is 136 times higher bioavailable than unformulated curcumin.CurcuWin is consists of 28\%turmeric powder, polyvinyl pyrrolidine, cellulosic derivatives, and natural antioxidants (Jäger et al., 2014).

Curcumin Pro

The whey protein encapsulation by spray drying method curcumin can improve its solubility. Around $100 \%$ increase in bioavailability is shown by this to prevent colon cancer. In different ratios, whey protein was used for nanoencapsulation such as 70:30, 50:50 and 35:65 to improve the bioavailability (W. Liu et al., 2016).

CurQfen $^{\mathrm{TM}}$

It is formulated by mixing up of turmeric powder with fenugreek soluble dietary fibres. The 
amorphous formulation delivers colloidal curcumin slowly to increase absorption. When compared to the treatment outcome of unformulated curcumin the bioavailability of formulated curcumin is $\mathbf{1 5 . 8}$ times more. The slow release from non-digestible soluble fibres leads to protection from enzymatic degradation and that is to be the possible mechanism of action for higher bioavailability (Im et al., 2012).

Theracurmin $^{\text {TM }}$

It is a preparation based on the colloidal nanoparticle. By the combined effect of improved solubility and reduced particle size, it is 16 times higher bioavailable than unformulated curcumin (Sasaki et al., 2011).

MicroActive curcumin

Micro active curcumin is prepared by $25 \%$ curcuminoids in a sustained release matrix. It consists of $25 \%$ curcumin, $16.7 \%$ panadon, $58 \%$ triacetin and sprays dried in porous silicon dioxide. It has 9.7 times higher bioavailability when compared to unformulated curcumin (Madhavi and Kagan, 2014).

LongVida $\AA$

It is formulated by mixing soy lecithin with turmeric powder, which contains purified phospholipids, vegetable stearic acid, docosahexaenoic acid, ascorbic acid (vitamin C), 5 esters, etc. The studies show that in humans, relative bioavailability is approximately $100 \%$ higher (Gota et al., 2010).

\section{CONCLUSION}

Curcuma longa or turmeric is a plant with an abundant treasure of medicinal values that should be selected for further research because of its proven activity against various diseases. The activity of curcumin against cardiovascular diseases, metabolic disorders, autoimmune disorders, and cancer shows a potent drug with fewer side effects. The higher therapeutic activity and lower bioavailability are the two contradictory points. So, to get the maximum benefits of curcumin as a potent drug, the formulations with maximum bioavailability should be studied and invented.

In this review article, we had gone through the various therapeutic activities of curcumin with a special emphasis on multi-drug resistant cancer cells, and different formulations of curcumin with higher bioavailability. The higher therapeutic efficacy of curcumin to reverse the multi-drug cancer cells are under study and the results light up to the possibility of combination therapy for cancer. The combination of phytoconstituents like curcumin with a conventional chemotherapeutic agent will make tremendous changes in the treatment outcome.

The lower bioavailability of curcumin can be improved by different additives like turmerone, piperine, quercetin etc. The major drawback of curcumin in clinical trials can be addressed with this and curcumin can be used as a better therapeutic agent for cancer prevention and treatment. This review paves the way for further studies on curcumin as an anti-cancer agent in multidrug-resistant cancer cells with higher water solubility and thereby higher bioavailability. Further studies should evolve to introduce curcumin and its higher bioavailability formulations as a potential therapeutic agent to treat multidrug-resistant cancer.

\section{ACKNOWLEDGEMENTS}

The authors are grateful to AICTE-NDF for providing financial support and JSS AHER, Mysuru, for providing the library resources and infrastructural facilities.

\section{REFERENCES}

Aggarwal, B.B., Kumar, A. and Bharti, A.C. (2003) 'Anticancer potential of curcumin: preclinical and clinical studies', Anticancer research, 23(1/A), pp. 363-398.

Aggarwal, S. et al. (2004) 'Inhibition of growth and survival of human head and neck squamous cell carcinoma cells by curcumin via modulation of nuclear factor- $\mathrm{B}$ signaling', International Journal of Cancer, 111(5), pp. 679-692. doi:10.1002/ijc.20333.

Alappat, L. and Awad, A.B. (2010) 'Curcumin and obesity: evidence and mechanisms', Nutrition Reviews, 68(12), pp. 729-738. doi:10.1111/j.1753-4887.2010.00341.x.

Antony, B. et al. (2008) 'A Pilot Cross-Over Study to Evaluate Human Oral Bioavailability of BCM95®CG (Biocurcumax ${ }^{\mathrm{TM}}$ ), A Novel Bioenhanced Preparation of Curcumin', Indian Journal of Pharmaceutical Sciences, $70(4)$, pp. 445-449. doi:10.4103/0250474X.44591.

Barthelemy, S. et al. (1998) 'Curcumin and curcumin derivatives inhibit Tat-mediated transactivation of type 1 human immunodeficiency virus long terminal repeat', Research in Virology, 149(1), pp. 4352. doi:10.1016/S0923-2516(97)86899-9.

Bengmark, S. (2006) 'Curcumin, An atoxic antioxidant and natural $\mathrm{Nf} \kappa \mathrm{B}$, 
cyclooxygenase-2, lipooxygenase, and inducible nitric oxide synthase inhibitor: A shield against acute and chronic diseases', Journal of Parenteral and Enteral Nutrition, $30(1)$, pp. $45-51$.

Cheng, A.L. et al. (2000) 'Phase I clinical trial of curcumin, a chemopreventive agent, in patients with high-risk or pre-malignant lesions', Anticancer research, 21, pp. 2895900.

Chiu, J. et al. (2009) 'Curcumin prevents diabetesassociated abnormalities in the kidneys by inhibiting p300 and nuclear factor- $\kappa B^{\prime}$, Nutrition, 25(9), pp. 964-972. doi:10.1016/j.nut.2008.12.007.

Chongtham, A. and Agrawal, N. (2016) 'Curcumin modulates cell death and is protective in Huntington's disease model', Scientific Reports, 6(1), $\quad$ p. 18736. doi:10.1038/srep18736.

Cuomo, J. et al. (2011) 'Comparative Absorption of a Standardized Curcuminoid Mixture and Its Lecithin Formulation', Journal of Natural Products, 74(4), pp. 664-669. doi:10.1021/np1007262.

Divya, C.S. and Pillai, M.R. (2006) 'Antitumor action of curcumin in human papillomavirus associated cells involves downregulation of viral oncogenes, prevention of NFkB and AP1 translocation, and modulation of apoptosis', Molecular Carcinogenesis, 45(5), pp. 320-332. doi:10.1002/mc.20170.

Eid, S.Y., El-Readi, M.Z. and Wink, M. (2012) 'Synergism of three-drug combinations of sanguinarine and other plant secondary metabolites with digitonin and doxorubicin in multi-drug resistant cancer cells', Phytomedicine, 19(14), pp. 1288-1297. doi:10.1016/j.phymed.2012.08.010.

Enrico, C. (2019) 'Chapter 3 - NanotechnologyBased Drug Delivery of Natural Compounds and Phytochemicals for the Treatment of Cancer and Other Diseases', in Atta-urRahman (ed.) Studies in Natural Products Chemistry. Elsevier, pp. 91-123. doi:10.1016/B978-0-444-64185-4.00003-4.

Faden, A.I. et al. (2016) 'Progressive inflammationmediated neurodegeneration after traumatic brain or spinal cord injury', British Journal of Pharmacology, 173(4), pp. 681691. doi:10.1111/bph.13179.

Farina, H.G. et al. (2006) 'Antitumor and antiangiogenic activity of soy isoflavone genistein in mouse models of melanoma and breast cancer', Oncology reports, 16(4), pp. 885-891.

Foryst-Ludwig, A. et al. (2004) 'Curcumin blocks $\mathrm{NF}-\kappa \mathrm{B}$ and the motogenic response in Helicobacter pylori-infected epithelial cells', Biochemical and Biophysical Research Communications, 316(4), pp. 1065-1072. doi:10.1016/j.bbrc.2004.02.158.

Funk, J.L. et al. (2006) 'Turmeric Extracts Containing Curcuminoids Prevent Experimental Rheumatoid Arthritis', Journal of Natural Products, 69(3), pp. 351-355. doi:10.1021/np050327j.

Ganjali, S. et al. (2017) 'HDL functionality in type 1 diabetes', Atherosclerosis, 267, pp. 99-109. doi:10.1016/j.atherosclerosis.2017.10.018.

Garcia-Alloza, M. et al. (2007) 'Curcumin labels amyloid pathology in vivo, disrupts existing plaques, and partially restores distorted neurites in an Alzheimer mouse model', Journal of Neurochemistry, 102(4), pp. 10951104. doi:10.1111/j.14714159.2007.04613.x.

Ghasemi, F. et al. (2019) 'Curcumin inhibits NF-kB and $W n t / \beta$-catenin pathways in cervical cancer cells', Pathology-Research and Practice, 215(10), p. 152556.

Gota, V.S. et al. (2010) 'Safety and Pharmacokinetics of a Solid Lipid Curcumin Particle Formulation in Osteosarcoma Patients and Healthy Volunteers', Journal of Agricultural and Food Chemistry, 58(4), pp. 2095-2099. doi:10.1021/jf9024807.

Grynkiewicz, G. and Ślifirski, P. (2012) 'Curcumin and curcuminoids in quest for medicinal status.', Acta Biochimica Polonica, 59(2). doi:10.18388/abp.2012_2139.

Handler, N. et al. (2007) 'Synthesis of novel curcumin analogues and their evaluation as selective cyclooxygenase-1 (COX-1) inhibitors', Chemical and pharmaceutical bulletin, 55(1), pp. 64-71.

Hewlings, S.J. and Kalman, D.S. (2017) 'Curcumin: A Review of Its' Effects on Human Health', Foods, 6(10), p. 92. doi:10.3390/foods6100092.

Hickey, M.A. et al. (2012) 'Improvement of neuropathology and transcriptional deficits in CAG 140 knock-in mice supports a beneficial effect of dietary curcumin in Huntington's disease', Molecular Neurodegeneration, 7(1), p. 12. doi:10.1186/1750-1326-7-12. 
Holt, P.R., Katz, S. and Kirshoff, R. (2005) 'Curcumin Therapy in Inflammatory Bowel Disease: A Pilot Study', Digestive Diseases and Sciences, 50(11), pp. 2191-2193. doi:10.1007/s10620-005-3032-8.

Hu, S. et al. (2018) 'Curcumin inhibits proliferation and promotes apoptosis of breast cancer cells', Experimental and Therapeutic Medicine, 16(2), pp. 1266-1272. doi:10.3892/etm.2018.6345.

Im, K. et al. (2012) 'An enhanced bioavailable formulation of curcumin using fenugreekderived soluble dietary fibre', Journal of Functional Foods, 4(1), pp. 348-357. doi:10.1016/j.jff.2012.01.004.

Jäger, R. et al. (2014) 'Comparative absorption of curcumin formulations', Nutrition Journal, 13(1), p. 11. doi:10.1186/1475-2891-13-11.

Karlstetter, M. et al. (2011) 'Curcumin is a potent modulator of microglial gene expression and migration', Journal of Neuroinflammation, 8(1), p. 125. doi:10.1186/1742-2094-8-125.

Kaur, G., Invally, M. and Chintamaneni, M. (2016) 'Influence of piperine and quercetin on antidiabetic potential of curcumin', Journal of Complementary and Integrative Medicine, 13(3), pp. 247-255.

Keihanian, F. et al. (2018) 'Curcumin, hemostasis, thrombosis, and coagulation', Journal of Cellular Physiology, 233(6), pp. 4497-4511. doi:10.1002/jcp.26249.

Khan, N. and Mukhtar, H. (2008) 'Multitargeted therapy of cancer by green tea polyphenols', Cancer Letters, 269(2), pp. 269-280. doi:10.1016/j.canlet.2008.04.014.

Kim, H. et al. (2005) 'Effects of Naturally Occurring Compounds on Fibril Formation and Oxidative Stress of $\beta$-Amyloid', Journal of Agricultural and Food Chemistry, 53(22), pp. 8537-8541. doi:10.1021/jf051985c.

Kim, H.J. et al. (2009) 'Antiviral effect of Curcuma longa Linn extract against hepatitis B virus replication', Journal of Ethnopharmacology, 124(2), pp. 189-196. doi:10.1016/j.jep.2009.04.046.

Koosirirat, C. et al. (2010) 'Investigation of the antiinflammatory effect of Curcuma longa in Helicobacter pylori-infected patients', International Immunopharmacology, 10(7), pp. 815-818. doi:10.1016/j.intimp.2010.04.021.

Kouhpeikar, H. et al. (2019) 'Curcumin as a therapeutic agent in leukemia', Journal of
Cellular Physiology, 234(8), pp. 1240412414. doi:10.1002/jcp.28072.

Kutluay, S.B. et al. (2008) 'Curcumin inhibits herpes simplex virus immediate-early gene expression by a mechanism independent of p300/CBP histone acetyltransferase activity', Virology, 373(2), pp. 239-247. doi:10.1016/j.virol.2007.11.028.

Lavoie, S. et al. (2009) 'Curcumin, quercetin, and tBHQ modulate glutathione levels in astrocytes and neurons: importance of the glutamate cysteine ligase modifier subunit', Journal of Neurochemistry, 108(6), pp. 14101422. doi:10.1111/j.14714159.2009.05908.x.

Lee, W.-H. et al. (2014) 'Recent advances in curcumin nanoformulation for cancer therapy', Expert Opinion on Drug Delivery, 11(8), pp. 1183-1201. doi: $10.1517 / 17425247.2014 .916686$.

Li, X. et al. (2014) 'Curcumin Modulates miR19/PTEN/AKT/p53 Axis to Suppress Bisphenol A-induced MCF-7 Breast Cancer Cell Proliferation', Phytotherapy Research, 28(10), pp. 1553-1560. doi:10.1002/ptr.5167.

Limtrakul, P., Anuchapreeda, S. and Buddhasukh, D. (2004) 'Modulation of human multidrugresistance MDR-1 gene by natural curcuminoids', BMC Cancer, 4(1), p. 13. doi:10.1186/1471-2407-4-13.

Liu, C.-H. and Huang, H.-Y. (2012) 'Antimicrobial Activity of Curcumin-Loaded Myristic Acid Microemulsions against Staphylococcus epidermidis', Chemical and Pharmaceutical Bulletin, 60(9), pp. 1118-1124. doi:10.1248/cpb.c12-00220.

Liu, H.-T. and Ho, Y.-S. (2018) 'Anticancer effect of curcumin on breast cancer and stem cells', Food science and human wellness, 7(2), pp. 134-137.

Liu, T. et al. (2017) 'Curcumin suppresses proliferation and in vitro invasion of human prostate cancer stem cells by ceRNA effect of miR-145 and IncRNA-ROR', Gene, 631, pp. 29-38. doi:10.1016/j.gene.2017.08.008.

Liu, W. et al. (2016) 'On enhancing the solubility of curcumin by microencapsulation in whey protein isolate via spray drying', Journal of Food Engineering, 169, pp. 189-195. doi:10.1016/j.jfoodeng.2015.08.034.

Liu, Z. et al. (2016) 'Evaluation of the efficacy of paclitaxel with curcumin combination in 
ovarian cancer cells', Oncology letters, 12(5), pp. 3944-3948.

Lopresti, A.L. et al. (2014) 'Curcumin for the treatment of major depression: A randomised, double-blind, placebo controlled study', Journal of Affective Disorders, 167, pp. 368-375. doi:10.1016/j.jad.2014.06.001.

Lopresti, A.L. et al. (2015) 'Curcumin and major depression: A randomised, double-blind, placebo-controlled trial investigating the potential of peripheral biomarkers to predict treatment response and antidepressant mechanisms of change', European Neuropsychopharmacology, 25(1), pp.

38-50. doi:10.1016/j.euroneuro.2014.11.015.

Lu, H.-F. et al. (2009) 'Curcumin-Induced DNA Damage and Inhibited DNA Repair Genes Expressions in Mouse-Rat Hybrid Retina Ganglion Cells (N18)', Neurochemical Research, 34(8), p. 1491. doi:10.1007/s11064-009-9936-5.

Madhavi, D. and Kagan, D. (2014) 'Bioavailability of a Sustained Release Formulation of Curcumin', Integrative Medicine: A Clinician's Journal, 13(3), pp. 24-30.

Meiyanto, E. et al. (2014) 'Curcumin and its Analogues (PGV-0 and PGV-1) Enhance Sensitivity of Resistant MCF-7 Cells to Doxorubicin through Inhibition of HER2 and NF-kB Activation', Asian Pacific Journal of Cancer Prevention, 15(1), pp. 179-184. doi:10.7314/APJCP.2014.15.1.179.

Mirzabeigi, P. et al. (2015) 'The Effect of Curcumin on some of Traditional and Non-traditional Cardiovascular Risk Factors: A Pilot Randomized, Double-blind, Placebocontrolled Trial', Iranian Journal of Pharmaceutical Research: IJPR, 14(2), pp. 479-486.

Misra, R. and Sahoo, S.K. (2011) 'Coformulation of Doxorubicin and Curcumin in Poly(d,llactide-co-glycolide) Nanoparticles Suppresses the Development of Multidrug Resistance in K562 Cells', Molecular Pharmaceutics, 8(3), pp. 852-866. doi:10.1021/mp100455h.

Moghaddam, K.M. et al. (2009) 'The combination effect of curcumin with different antibiotics against Staphylococcus aureus', International Journal of Green Pharmacy (IJGP), 3(2). doi:10.22377/ijgp.v3i2.70.
Mohammad, I.S. et al. (2019) 'Drug-delivering-drug approach-based codelivery of paclitaxel and disulfiram for treating multidrug-resistant cancer', International Journal of Pharmaceutics, 557, pp. 304-313. doi:10.1016/j.ijpharm.2018.12.067.

Mortezaee, K. et al. (2019) 'NF-кB targeting for overcoming tumor resistance and normal tissues toxicity', Journal of Cellular Physiology, 234(10), pp. 17187-17204. doi:10.1002/jcp.28504.

Orellana-Paucar, A.M. et al. (2013) 'Insights from zebrafish and mouse models on the activity and safety of ar-turmerone as a potential drug candidate for the treatment of epilepsy', PloS One, 8(12), p. e81634. doi:10.1371/journal.pone.0081634.

Pan, Y., Zheng, Y.M. and Ho, W.S. (2018) 'Effect of quercetin glucosides from Allium extracts on HepG2, PC-3 and HT-29 cancer cell lines', Oncology Letters, 15(4), pp. 4657-4661. doi:10.3892/ol.2018.7893.

Panahi, Y. et al. (2014) 'Curcuminoid Treatment for Knee Osteoarthritis: A Randomized DoubleBlind Placebo-Controlled Trial', Phytotherapy Research, 28(11), pp. 16251631. doi:10.1002/ptr.5174.

Panahi, Y. et al. (2019) 'Efficacy of phospholipidated curcumin in nonalcoholic fatty liver disease: a clinical study', Journal of Asian Natural Products Research, 21(8), pp. 798-805. doi:10.1080/10286020.2018.1505873.

Patil, S. et al. (2015) 'Enhanced oral bioavailability and anticancer activity of novel curcumin loaded mixed micelles in human lung cancer cells', Phytomedicine, 22(12), pp. 11031111.

Peng, S.-F. et al. (2014) 'Curcumin-loaded nanoparticles enhance apoptotic cell death of U2OS human osteosarcoma cells through the Akt-Bad signaling pathway', International Journal of Oncology, 44(1), pp. 238-246. doi:10.3892/ijo.2013.2175.

Prasad, S. and Tyagi, A.K. (2015) 'Curcumin and its analogues: a potential natural compound against HIV infection and AIDS', Food \& Function, 6(11), pp. 3412-3419. doi:10.1039/C5F000485C.

Prusty, B.K. and Das, B.C. (2005) 'Constitutive activation of transcription factor AP-1 in cervical cancer and suppression of human papillomavirus (HPV) transcription and AP1 activity in HeLa cells by curcumin', 
International Journal of Cancer, 113(6), pp. 951-960. doi:10.1002/ijc.20668.

Purpura, M. et al. (2018) 'Analysis of different innovative formulations of curcumin for improved relative oral bioavailability in human subjects', European journal of nutrition, 57(3), pp. 929-938.

Rai, D. et al. (2008) 'Curcumin inhibits FtsZ assembly: an attractive mechanism for its antibacterial activity', Biochemical Journal, 410(1), pp. 147-155. doi:10.1042/BJ20070891.

Ranjan, A.P. et al. (2012) 'Scale up, optimization and stability analysis of Curcumin C3 complexloaded nanoparticles for cancer therapy', Journal of Nanobiotechnology, 10(1), pp. 118.

Ranjan, P., Mohapatra, B. and Das, P. (2020) $A$ rational drug designing: What bioinformatics approach tells about the wisdom of practicing traditional medicines for screening the potential of Ayurvedic and natural compounds for their inhibitory effect against COVID-19 Spike, Indian strain Spike, Papainlike protease and Main Protease protein. preprint. In Review. doi:10.21203/rs.3.rs30366/v1.

Rauf, A. et al. (2018) 'Resveratrol as an anti-cancer agent: A review', Critical Reviews in Food Science and Nutrition, 58(9), pp. 1428-1447. doi:10.1080/10408398.2016.1263597.

Rivera, M. et al. (2017) 'Targeting multiple proapoptotic signaling pathways with curcumin in prostate cancer cells', PLOS ONE, 12(6), p. e0179587. doi:10.1371/journal.pone.0179587.

Rowe, D.L. et al. (2009) 'Modulation of the BRCA1 Protein and Induction of Apoptosis in Triple Negative Breast Cancer Cell Lines by the Polyphenolic Compound Curcumin', Breast Cancer: Basic and Clinical Research, 3, p. BCBCR.S3067. doi:10.4137/BCBCR.S3067.

Rudrappa, T. and Bais, H.P. (2008) 'Curcumin, a known phenolic from Curcuma longa, attenuates the virulence of Pseudomonas aeruginosa PAO1 in whole plant and animal pathogenicity models', Journal of agricultural and food chemistry, 56(6), pp. 1955-1962.

Saja, K. et al. (2007) 'Anti-inflammatory effect of curcumin involves downregulation of MMP9 in blood mononuclear cells', International immunopharmacology, 7(13), pp. 16591667.
Sanmukhani, J. et al. (2014) 'Efficacy and Safety of Curcumin in Major Depressive Disorder: A Randomized Controlled Trial', Phytotherapy Research, 28(4), pp. 579-585. doi:10.1002/ptr.5025.

Santos, A.M. et al. (2015) 'Curcumin Inhibits Gastric Inflammation Induced by Helicobacter Pylori Infection in a Mouse Model', Nutrients, 7(1), pp. 306-320. doi:10.3390/nu7010306.

Sasaki, H. et al. (2011) 'Innovative preparation of curcumin for improved oral bioavailability', Biological and Pharmaceutical Bulletin, 34(5), pp. 660-665.

Saydmohammed, M., Joseph, D. and Syed, V. (2010) 'Curcumin suppresses constitutive activation of STAT-3 by up-regulating protein inhibitor of activated STAT-3 (PIAS3 ) in ovarian and endometrial cancer cells', Journal of Cellular Biochemistry, 110(2), pp. 447-456. doi:10.1002/jcb.22558.

Schaffer, M. et al. (2011) 'Curcuma as a functional food in the control of cancer and inflammation', Current Opinion in Clinical Nutrition and Metabolic Care, 14(6), pp. 588597. doi:10.1097/MC0.0b013e32834bfe94.

Schiborr, C. et al. (2014) 'The oral bioavailability of curcumin from micronized powder and liquid micelles is significantly increased in healthy humans and differs between sexes', Molecular nutrition \& food research, 58(3), pp. 516-527.

Sharma, N. and Nehru, B. (2018) 'Curcumin affords neuroprotection and inhibits $\alpha$-synuclein aggregation in lipopolysaccharide-induced Parkinson's disease model', Inflammopharmacology, 26(2), pp. 349-360. doi:10.1007/s10787-017-0402-8.

Shishodia, S. et al. (2005) 'Curcumin (diferuloylmethane) inhibits constitutive NF- $\kappa \mathrm{B}$ activation, induces G1/S arrest, suppresses proliferation, and induces apoptosis in mantle cell lymphoma', Biochemical Pharmacology, 70(5), pp. 700713. doi:10.1016/j.bcp.2005.04.043.

Singla, V. et al. (2014) 'Induction with NCB-02 (curcumin) enema for mild-to-moderate distal ulcerative colitis - A randomized, placebo-controlled, pilot study', Journal of Crohn's and Colitis, 8(3), pp. 208-214. doi:10.1016/j.crohns.2013.08.006.

$\mathrm{Su}, \mathrm{L}$., Wang, Y. and Chi, H. (2017) 'Effect of curcumin on glucose and lipid metabolism, FFAs and TNF- $\alpha$ in serum of type 2 diabetes mellitus rat models', Saudi Journal of 
Biological Sciences, 24(8), pp. 1776-1780. doi:10.1016/j.sjbs.2017.11.011.

Sui, H., Fan, Z.Z. and Li, Q. (2012) 'Signal transduction pathways and transcriptional mechanisms of ABCB1/Pgp-mediated multiple drug resistance in human cancer cells', Journal of International Medical Research, 40(2), pp. 426-435.

Sui, Z. et al. (1993) 'Inhibition of the HIV-1 and HIV2 proteases by curcumin and curcumin boron complexes', Bioorganic \& Medicinal Chemistry, 1(6), pp. 415-422. doi:10.1016/S0968-0896(00)82152-5.

Tang, C. et al. (2018) 'Effect of $\beta$-elemene on the kinetics of intracellular transport of $d$ luciferin potassium salt ( $\mathrm{ABC}$ substrate) in doxorubicin-resistant breast cancer cells and the associated molecular mechanism', European Journal of Pharmaceutical Sciences, 120, pp. 20-29. doi:10.1016/j.ejps.2018.04.037.

Tęcza, P. and Żylińska, L. (2016) '[Preventive effects of curcumin and resveratrol in Alzheimer's disease]', Przeglad lekarski, 73(5), pp. 320-323.

Toden, S. et al. (2017) 'Essential turmeric oils enhance anti-inflammatory efficacy of curcumin in dextran sulfate sodium-induced colitis', Scientific reports, 7(1), pp. 1-12.

Tripanichkul, W. and Jaroensuppaperch, E. (2012) 'Curcumin Protects Nigrostriatal Dopaminergic Neurons and Reduces Glial Activation in 6-Hydroxydopamine Hemiparkinsonian Mice Model', International Journal of Neuroscience, 122(5), pp. 263-270. doi:10.3109/00207454.2011.648760.

Tseng, Y.-H. et al. (2019) 'Curcumin and tetrahydrocurcumin induce cell death in Ara-C-resistant acute myeloid leukemia', Phytotherapy Research, 33(4), pp. 11991207. doi:10.1002/ptr.6316.

Ungphaiboon, S. et al. (2005) 'Study on antioxidant and antimicrobial activities of turmeric clear liquid soap for wound treatment of HIV patients', 27, p. 10.

Unlu, A. et al. (2016) 'Curcumin (Turmeric) and cancer', J buon, 21(5), pp. 1050-1060.
Waghmare, P.R. et al. (2017) 'Turmeric as medicinal plant for the treatment of acne vulgaris', PharmaTutor, 5(4), pp. 19-27.

Wang, C. et al. (2019) 'Curcumin exerts cytotoxicity dependent on reactive oxygen species accumulation in non-small-cell lung cancer cells', Future Oncology, 15(11), pp. 12431253. doi:10.2217/fon-2018-0708.

Weber, W.M. et al. (2006) 'TPA-induced upregulation of activator protein-1 can be inhibited or enhanced by analogs of the natural product curcumin', Biochemical pharmacology, 72(8), pp. 928-940.

Xia, L. et al. (2018) 'Role of the NFKB-signaling pathway in cancer', OncoTargets and therapy, 11, pp. 2063-2073. doi:10.2147/OTT.S161109.

Xie, L. et al. (2009) 'Amelioration of experimental autoimmune encephalomyelitis by curcumin treatment through inhibition of IL-17 production', International Immunopharmacology, 9(5), pp. 575-581. doi:10.1016/j.intimp.2009.01.025.

Yang, L. et al. (2011) 'Reversal of multidrug resistance in human breast cancer cells by Curcuma wenyujin and Chrysanthemum indicum', Phytomedicine, 18(8), pp. 710718. doi:10.1016/j.phymed.2010.11.017.

Zhang, J. et al. (2014) ' $\beta$-Elemene Reverses Chemoresistance of Breast Cancer via Regulating MDR-Related MicroRNA Expression', Cellular Physiology and Biochemistry, 34(6), pp. 2027-2037. doi:10.1159/000366398.

Zhang, L. et al. (2012) A novel folate-modified selfmicroemulsifying drug delivery system of curcumin for colon targeting, International Journal of Nanomedicine. Dove Press. doi:10.2147/IJN.S27639.

Zhong, Z. et al. (2018) 'Anti-cancer effects of Rhizoma Curcumae against doxorubicinresistant breast cancer cells', Chinese Medicine, 13(1), p. 44. doi:10.1186/s13020018-0203-z.

Zoi, V. et al. (2021) 'The Role of Curcumin in Cancer Treatment', Biomedicines, 9(9), p. 1086. 